\title{
O SISTEMA DE LOGÍSTICA REVERSA COMO FORMA DE DESENVOLVIMENTO DAS EMPRESAS BRASILEIRAS: O CAMINHO DO CAPITAL NATURAL
}

\author{
João Ricardo Holanda do Nascimento \\ Mestrando em Direito pela Unichristus; Especialização em Direito Constitucional (em \\ andamento) pela Damásio de Jesus, Graduado em Direito pela Faculdade Luciano Feijão. \\ Advogado Assessor da Defensoria Pública Geral do Estado do Ceará. \\ Email: jricardo_direito@yahoo.com.br
}

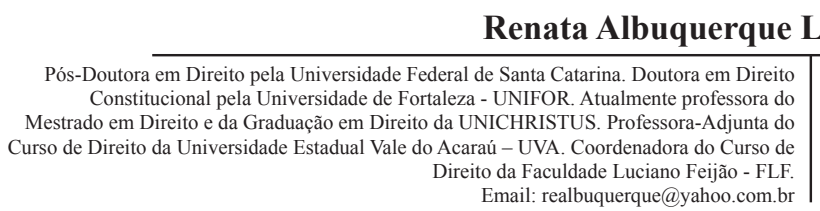

\section{RESUMO}

O arcabouço legislativo ambiental brasileiro sofreu a inclusão, dentre os reforços positivados pela Lei $\mathrm{n}^{\mathrm{o}}$ 12.305/2010 (Política Nacional de Resíduos Sólidos), do Sistema de Logística Reversa, que tem como objetivo a responsabilização de todos os atores do ciclo de vida dos produtos, pela sua destinação final. Dentre os responsabilizados, inclui-se a sociedade empresarial brasileira, a exemplo de fabricantes, distribuidores e comerciários, que passam, a partir da inovação legislativa, a ter mais um ônus legal na atuação corporativa. O presente trabalho, por meio de pesquisa bibliográfica, visou conceituar o sistema de logística reversa, ainda pouco debatido no Brasil, a fim de verificar a sua aplicabilidade nas organizações brasileiras, não como um ônus à finalidade central lucrativa, mas como um meio plausível de direcioná-las à sustentabilidade, segundo o conceito de capital natural, sob o viés defendido por Tercek e Adamns, com a possibilidade de ser uma alternativa capaz de desenvolver as empresas de forma lucrativa e, ao mesmo tempo, sustentável.

Palavras-chave: Logística Reversa; Empresas Brasileiras; Capital Natural. 
THE REVERSE LOGISTICS SYSTEM AS A FORM OF DEVELOPMENT OF BRAZILIAN COMPANIES: THE WAY OF NATURAL CAPITAL.

\begin{abstract}
$A B S T R A C T$
The Brazilian environmental legislative framework has been included in the Reverse Logistics System, among the reinforcements approved by Law No. 12,305 / 2010 (National Solid Waste Policy), which aims to hold all stakeholders in the product life cycle, by its final destination. Among those responsible, the Brazilian business community is included, such as manufacturers, distributors and traders, who, through legislative innovation, have another legal burden on corporate performance. The present work, through a bibliographical research, aimed to conceptualize the reverse logistics system, still little debated in Brazil, in order to verify its applicability in Brazilian organizations, not as a burden to the central profit objective, but as a plausible means of and to direct them to sustainability, according to the concept of natural capital, under the bias advocated by Tercek and Adamns, with the possibility of being an alternative capable of developing profitable and at the same time sustainable companies.
\end{abstract}

Keywords: Reverse logistic; Brazilian Companies; Natural Capital. 


\section{INTRODUÇÃO}

A política nacional de resíduos sólidos, criada por meio da Lei $\mathrm{n}^{\mathrm{o}} 12.305 / 2010$, é mais um mecanismo legislativo que visou estabelecer determinados critérios ambientais a serem respeitados pelo Estado, por pessoas físicas e também jurídicas, no Brasil.

Com o viés participativo, emanado de ideias basilares, tal qual elencar como um de seus princípios a valorização do catador, a lei apresenta também, como um complemento ao sistema de logística já vigente, o sistema de logística reversa, que determina a responsabilidade pelo destino final dos resíduos sólidos dos atores que participam do ciclo de vida dos produtos, inseridos nesse rol os consumidores, bem como as empresas nacionais.

Esse rol extenso é justificado ante a definição da amplitude do ciclo de vida dos produtos, assim identificada por Valle (2002, p. 145) como "a análise do Ciclo de Vida de um Produto compreende desde a extração dos recursos naturais ou matérias-primas, necessários à sua produção, até a disposição final do produto ao fim de sua vida útil”.

O presente trabalho, ao analisar o conceito do sistema de logística reversa, distinguindo os produtos que a lei elenca como de obrigatória análise junto à sua logística, bem como os responsáveis elencados pela norma para realizarem as funções no sistema, de modo que haja o mínimo de entropia possível, pretende verificar as divergências doutrinárias entre os que defendem a atuação empresarial livre e a de quem pretende sugerir uma atuação sustentável das companhias.

Verifica-se aqui entropia, da forma como conceituada por Greco, que confere a sua definição como sendo "a medida da desordem de um sistema. Quanto maior a entropia, maior é o grau de desordem de um sistema" (2015, p. 58). Desse modo, defende-se que o sistema de logística reversa pode, ao ser utilizado da forma correta, influenciar para a diminuição ou contenção da entropia natural do ecossistema.

Nas teorias capitalistas hodiernas, existem alguns doutrinadores que defendem a ausência de intervenção estatal na economia, como pode ser observado na doutrina de Hayek (2010), ao aduzir que uma mínima intervenção acaba gerando alguma imperfeição no ciclo econômico, de modo que deverá ser corrigida por nova intervenção, formando-se um ciclo no qual a liberdade do mercado seria tolhida e prejudicada pelo Estado.

Nas palavras de Vidal: 
Em outras palavras, Hayek argumenta que as imperfeições causadas pela intervenção estatal numa economia capitalista de livre mercado geram demandas por uma nova intervenção, justamente para a correção das referidas imperfeições. Seguir-se-ão, desse modo, sucessivas rodadas intervencionistas, até que bem pouco ou nada restará de um capitalismo do tipo concorrencial. Aí se está, tanto para o autor como para outros liberais, diante da emergência de qualquer das variantes do socialismo, que se converte, ademais, em totalitarismo. (VIDAL, 2007).

Nessa vertente, Robert Reich (2008) analisa o atual sistema capitalista, mormente o norte-americano, para estruturar a sua teoria do supercapitalismo, a partir do qual verifica que a tendência atual do sistema capitalista é o afastamento das empresas de questões morais, éticas ou ambientais, que demandem discussões as quais podem resultar em queda dos rendimentos financeiros.

De outra monta, Tercek e Adams (2014) propõem uma maior participação corporativa no que diz respeito à sobrevivência e ao bem-estar de todos, para uma melhor harmonização com o meio ambiente natural.

Essa proposta é defendida pelos autores, mesmo em um cenário onde todas as ações se interligam por meio da urgência na comunicação e conexão nas relações, com a ascensão das ferramentas tecnológicas, bem como a aceleração do crescimento industrial, o que gera relações mais elásticas e fragilizadas entre empresas-indivíduos.

Nessa esteira, como identifica Reich (2008), algumas organizações tendem a se apresentar com o discurso proativo e identificado com causas nobres da sociedade, como é o caso da seara ambiental.

$\mathrm{Na}$ modernidade líquida, conceito criado por Zygmunt wBauman (2001), contudo, não se sabe se o que buscam essas organizações é o reconhecimento da sociedade em geral, a fim de obter maiores lucros por buscas aos seus produtos ou, de fato, um engajamento ao percurso sustentável. Tercek e Adams (2014) identificam que as organizações podem e devem, a despeito de se preocuparem tão somente com a mídia positiva, se direcionar ao caminho da sustentabilidade empresarial, sem que isso signifique perda de competitividade no mercado.

Em um estudo com metodologia bibliográfica, o presente trabalho apresenta as ideias de Reich (2008) e Tercek e Adams (2014, de modo a expor a realidade atual das organizações em sua relação com o meio ambiente, bem como, dando foco à defesa de que as empresas podem optar por escolhas sustentáveis, como o sistema de logística reversa, persistindo 
com a tendência de serem lucrativas e, ao mesmo tempo, ambientalmente adequadas.

Nesse sentido, as companhias, ao observarem os mecanismos sustentáveis na sua atuação ordinária, podem também estar promovendo a sua própria subsistência no ecossistema, posto que contribuiriam para o desenvolvimento sustentável do planeta, o que envolve seus próprios acionistas, consumidores e distribuidores.

A logística reversa, do modo proposto pela PNRS, se apresenta como uma forma de intervenção estatal na economia, defendida aqui como uma intervenção democrática, numa perspectiva construtiva da democracia, como defendida por Coutinho (2016), por tratar da defesa ao meio ambiente equilibrado, direito fundamental elencado no rol trazido pelo legislador constituinte na carta magna de 1988.

Desse modo, analisar-se-á que a ideia se mostra como um mecanismo capaz de ser utilizado pelas organizações brasileiras, até mesmo como uma maneira moderna de voltar o pensamento empresarial do país para a sustentabilidade, como uma forma viável de desenvolvimento.

\section{O SISTEMA DE LOGÍSTICA REVERSA DA POLÍTICA NACIONAL DE RESÍDUOS SÓLIDOS}

A Política Nacional de Resíduos Sólidos (PNRS) possui como um de seus objetivos a não geração de resíduos e, nesse sentido, possui mecanismos tendentes a prevenir a produção acelerada do lixo, tal qual o sistema de logística reversa, que visa, como um sistema puro, conter a entropia, ou seja, a desordem, do sistema ambiental.

Tal instrumento visa reduzir a quantidade de resíduos sólidos, por meio do planejamento dos fabricantes, visando que o consumidor reutilize a embalagem, prometendo reduzir o desperdício e o prejuízo ao meio ambiente. Seu conceito é facilmente encontrado no artigo $3^{\circ}$. XI da Lei em questão:

\footnotetext{
XI - logística reversa: instrumento de desenvolvimento econômico e social caracterizado por um conjunto de ações, procedimentos e meios destinados a viabilizar a coleta e a restituição dos resíduos sólidos ao setor empresarial, para reaproveitamento, em seu ciclo ou em outros ciclos produtivos, ou outra destinação final ambientalmente adequada.
} 
O sistema de logística reversa visa levar o rejeito à fonte de sua produção ou à cadeia de comercialização, com a finalidade específica de que haja seu reaproveitamento. É um procedimento que enseja a aplicação da responsabilidade pós-consumo, representando a aplicação do princípio do poluidor-pagador, um dos norteadores da PNRS.

A logística reversa poderá ser implementada por meio de acordos setoriais, regulamentos expedidos pelo poder público e termos de compromisso, para o fim de responsabilizar, de forma compartilhada, os usuários (ou produtores) pelo ciclo de vida dos produtos.

Além desses mecanismos, a logística reversa pode ser implementada por meio do incentivo aos catadores de materiais reutilizáveis e recicláveis, ponto crucial para a presente análise, e também a partir da cooperação técnica e financeira entre os setores público e privado, com o fim de desenvolvimento de pesquisas de novos produtos, entre outros métodos, com a finalidade de disposição final ambientalmente adequada dos rejeitos.

Tendo em vista, sobretudo, os princípios do Direito Administrativo, o sistema de logística reversa deve ser realizado de forma independente do serviço público de limpeza urbana e de manejo dos resíduos sólidos, confome preconiza o artigo 33, caput, da Lei $\mathrm{n}^{\mathrm{o}}$ 12.305/10.

Se ocorrer de o serviço público, por acordo setorial ou termo de compromisso, encarregar-se das obrigações dos fabricantes, importadores, distribuidores e comerciantes, deverá haver remuneração, de acordo com o artigo $33, \S 7^{\circ}$, não podendo tal serviço ocorrer gratuitamente.

\subsection{Atividades abrangidas pelo sistema de logística reversa.}

$\mathrm{O}$ artigo 33 da Lei ${ }^{\circ}$ 12.305/10 elenca rol de atividades em que o sistema de logística reversa deverá se perfazer com obrigatoriedade:

Art. 33. São obrigados a estruturar e implementar sistemas de logística reversa, mediante retorno dos produtos após o uso pelo consumidor, de forma independente do serviço público de limpeza urbana e de manejo dos resíduos sólidos, os fabricantes, importadores, distribuidores e comerciantes de:

I - agrotóxicos, seus resíduos e embalagens, assim como outros produtos cuja embalagem, após o uso, constitua resíduo perigoso, observadas as regras de gerenciamento de resíduos perigosos previstas em lei ou regulamento, em normas estabelecidas pelos órgãos do Sisnama, do SNVS e do Suasa, ou em normas 


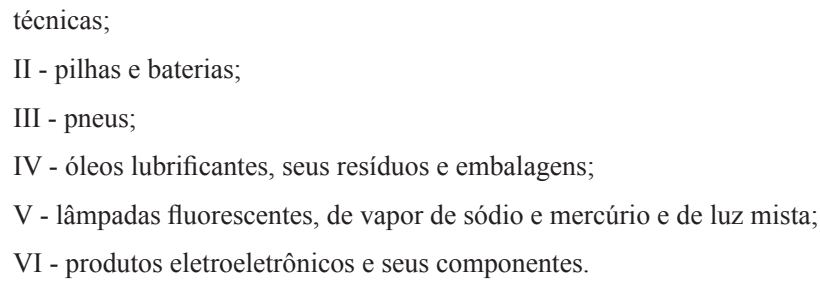

Ao analisar o disposto em lei, percebe-se que a obrigatoriedade da aplicação do sistema de logística reversa quanto aos agrotóxicos, pilhas e baterias, pneus e óleos lubrificantes, seus resíduos e embalagens, previstos nos incisos I a IV, prescinde de qualquer regulamento, acordo setorial ou termo de compromisso, conforme o disposto no Decreto $\mathrm{n}^{0} 7.404 \mathrm{de}$ 2010, sendo que o dever de operacionalização decorre da própria Política Nacional de Resíduos Sólidos. Cumpre ressaltar que a responsabilidade das empresas produtoras de agrotóxicos ou que comercializam esses produtos foi introduzida no ano de 2000, pela Lei ${ }^{\circ} 9.974$.

A logística reversa deve ser implantada em relação a lâmpadas fluorescentes, de vapor de sódio e mercúrio e de luz mista, bem como em relação aos produtos eletroeletrônicos e seus componentes, exceção criada no artigo 56 da lei. Convém aduzir que a implementação deverá ser progressiva, segundo cronograma estabelecido em regulamento, fazendo com que exista uma distinção entre as formas de implementação, sendo a primeira chamada de implementação imediata (artigo 33, I a IV) e a segunda de implementação progressiva, conforme o artigo 56 cumulado com o artigo 33, V e VI.

Por sua vez, o parágrafo primeiro do artigo 33 adota a possibilidade de extensão da obrigatoriedade por meio de regulamento ou de acordos setoriais e termos de compromisso, quanto a produtos comercializados em embalagens plásticas, metálicas ou de vidro e aos demais produtos e embalagens.

Neste caso, a definição dos produtos e embalagens deverá considerar a viabilidade técnica e econômica da logística reversa, bem como o grau e a extensão do impacto à saúde pública e ao meio ambiente quanto aos resíduos gerados; portanto, o rol elencado pelo artigo 33 não é taxativo.

Desse modo, a própria lei já diferencia, novamente, os tipos de produtos, embalagens e resíduos atingidos pelo sistema de logística reversa, sendo que os estabelecidos no artigo 33, incisos I a VI, prescindem 
de posterior procedimento a ser feito, por ser considerado causador de impacto à saúde pública e ao meio ambiente (ainda que com prazo de vigência diferente) e os do segundo rol, descritos no parágrafo primeiro do artigo 33, como sendo dependentes de análise prévia para serem inseridos no sistema de logística reversa.

\subsection{Medidas de implementação e operacionalização do sistema de logística reversa}

Ainda no artigo 33 da Política Nacional de Resíduos Sólidos, mais precisamente nos parágrafos $4^{\circ}$ ao $6^{\circ}$, estão distribuídos os deveres das diferentes categorias de responsáveis em relação à logística reversa, tendo buscado a lei atingir o maior número de deveres em prol das medidas ambientalmente adequadas, além de elencar tais ônus de modo proporcional a cada espécie de categoria, uma inovação legislativa que distribui a responsabilidade pela proteção ao meio ambiente equilibrado, princípio consagrado no texto da Constituição Federal de 1988, a todos os atores do processo de produção e destinação final dos resíduos.

\subsubsection{Quanto aos consumidores}

Antes da destinação final dos resíduos sólidos, a maioria dos produtos passa pelas mãos dos consumidores que, de acordo com a Lei $\mathrm{n}^{\mathrm{o}}$ 12.305 de 2010, após o uso dos produtos e embalagens que forem objeto da logística reversa, deverão efetuar a devolução destes aos comerciantes e distribuidores, pois o gerador de resíduos domiciliares tem cessada a sua responsabilidade pelos resíduos com a disponibilização adequada para a coleta e com a devolução, para os casos do artigo 33, em respeito ao artigo 28 da lei que assim prescreve:“"[a]rt. 28. O gerador de resíduos sólidos domiciliares tem cessada sua responsabilidade pelos resíduos com a disponibilização adequada para a coleta ou, nos casos abrangidos pelo art. 33, com a devolução".

Contudo, os consumidores poderão ser responsabilizados se dispuserem os resíduos a sujeitos não previstos na Lei $\mathrm{n}^{\circ} 12.305$, como, igualmente, se deixarem de lançar ou assim o façam em locais inadequados, ou seja, em desconformidade com o texto legal.

Assim como todos os sujeitos munidos de direitos e deveres, os consumidores são chamados pela PNRS a consumir de forma sustentável, 
sendo este um de seus objetivos, positivado no artigo $7^{\circ}$, inciso XV. Ou seja, há uma ligação inegável entre a geração de resíduos e o consumo e, por isso, a lei colocou um dos eixos da cadeia de responsabilidade à pessoa do consumidor.

Para fins de integração com o poder público na concretização do positivado pela PNRS, bem como para a fiscalização de seu cumprimento, a lei determinou a existência de planos municipais de gestão integrada de resíduos sólidos, com a disposição do sistema de coleta seletiva, na forma dos artigos 18 e 19 da PNRS. Quando da aplicação do sistema de logística reversa, os consumidores são obrigados, conforme o artigo 35 da lei, a acondicionar adequadamente e de forma diferenciada os resíduos sólidos gerados ea disponibilizar adequadamente os resíduos sólidos reutilizáveis e recicláveis para a coleta ou devolução, tendo o Poder Público Municipal a faculdade de estabelecer sanções administrativas, como multas, para as pessoas físicas ou jurídicas que não fizerem o devido acondicionamento $\mathrm{e}$ disponibilização adequada dos resíduos sólidos reutilizáveis e recicláveis.

Contudo, ao tratar acerca da possibilidade da concessão de incentivos econômicos aos consumidores que cumprirem as obrigações do artigo 35, a PNRS está, de certo modo, impulsionando os municípios a darem este passo para o início dessa política pública ambiental, o que parece ter sido a proposta sugerida pelo poder constituído ao legislar nesse sentido.

Assim, a PNRS criou mecanismos de intervenção estatal na vida dos consumidores, bem como dos outros atores do processo de criação, utilização e destinação final dos resíduos sólidos. Resta pontuar, contudo, se tal intervenção pode ser considerada democrática.

\subsubsection{Quanto aos comerciantes, distribuidores, fabricantes e importadores}

A Lei $\mathrm{n}^{\mathrm{o}} 12.305 / 10$ positiva os deveres dos comerciantes, distribuidores, fabricantes e importadores, conforme se verifica da análise de seu artigo $33, \S 3^{\circ}$ :

§ 3 Sem prejuízo de exigências específicas fixadas em lei ou regulamento, em normas estabelecidas pelos órgãos do Sisnama e do SNVS, ou em acordos setoriais e termos de compromisso firmados entre o poder público e o setor empresarial, cabe aos fabricantes, importadores, distribuidores e comerciantes dos produtos a que se 
referem os incisos II, III, V e VI ou dos produtos e embalagens a que se referem os incisos I e IV do caput e o $\S 1^{\circ}$ tomar todas as medidas necessárias para assegurar a implementação e operacionalização do sistema de logística reversa sob seu encargo, consoante o estabelecido neste artigo, podendo, entre outras medidas:

I - implantar procedimentos de compra de produtos ou embalagens usados;

II - disponibilizar postos de entrega de resíduos reutilizáveis e recicláveis;

III - atuar em parceria com cooperativas ou outras formas de associação de catadores de materiais reutilizáveis e recicláveis, nos casos de que trata o $\S 1^{\circ}$.

Ao utilizar a expressão "podendo, entre outras medidas", a PNRS não está sugerindo, mas, sim,impondo três tipos de procedimentos aos destinatários da lei: 1) o de implantar procedimentos de compra de produtos ou embalagens usados; 2) disponibilizar postos de entrega de resíduos reutilizáveis e recicláveis; 3) atuar em parceria com cooperativas ou outras formas de associação de catadores de materiais reutilizáveis e recicláveis, nos casos de que trata do parágrafo primeiro do artigo 33.

Neste caso, os comerciantes e distribuidores deverão efetuar a devolução aos fabricantes ou aos importadores dos produtos e embalagens reunidos ou devolvidos na forma dos parágrafos $3^{\circ}$ e $4^{\circ}$ do artigo 33 , sendo que a paralisação na cadeia de restituição dos produtos utilizados ou a sua estocagem inadequada implica em responsabilidade destes profissionais.

Os fabricantes e importadores deverão dar aos produtos e embalagens reunidos e devolvidos a destinação ambientalmente adequada, devendo ser o rejeito encaminhado para disposição, na forma estabelecida pelo órgão competente do Sistema Nacional do Meio Ambiente (SISNAMA) e, se houver, pelo plano municipal de gestão integrada de resíduos sólidos, de acordo com o parágrafo $6^{\circ}$ do artigo 33 .

Ainda versando sobre fabricantes e importadores, cabe considerar que eles terão duplo dever, um referente aos produtos e embalagens e outro relacionado aos rejeitos. Quanto aos produtos e embalagens, eles serão possivelmente submetidos à reciclagem ou à reutilização.

Por sua vez, em relação aos rejeitos, isto é,aos resíduos que, após o esgotamento de todas as possibilidades de tratamento e recuperação pelos processos tecnológicos disponíveis e economicamente viáveis, só apresentem possibilidade de sua disposição final ambientalmente adequada - na maioria dos casos, o aterro-, os fabricantes e importadores deverão gozar de um aterro privado, que deverá ser monitorado e inspecionado pelo Poder Público. 
Como já dito acima e conforme Machado:

Aplica-se na logística reversa o princípio do poluidor-pagador, acolhido na Lei 12.305 (art. $6^{\circ}$, II), não podendo os geradores de resíduos transferirem, à sociedade ou à população, os encargos financeiros decorrentes de suas atividades, aplicando-se o brocardo ubiemolumentum, ibionus, pois onde há lucro ou proveito, deve haver contraprestação. (MACHADO, p. 61, 2012).

Configura-se como uma das novidades da PNRS a responsabilização de fabricantes e importadoresna gestão dos rejeitos provenientes dos produtos que fabricarem, não lhes cabendo criarem áreas contaminadas, mas áreas onde a degradação ambiental seja evitada, monitorada e, se necessário, remediada.

\section{COMO CONCILIAR O DESENVOLVIMENTO ECONÔMICO EMPRESARIAL COM A SUSTENTABILIDADE? A LOGÍSTICA REVERSA COMO UM SISTEMA PLAUSÍVEL}

Como, na atual sociedade moderna, produzir e garantir lucros sendo, ao mesmo tempo, sustentável? Como garantir o pleno funcionamento do sistema empresarial, tendo que se submeter a regras propostas por meio de intervenção estatal, de modo a observar o respeito ao direito fundamental ao meio ambiente? Esse é o desafio atual das organizações.

O capitalismo já se mostrou como a forma mais adequada à ideia de liberalismo econômico, de acordo com Rosenfield (2010). Desse modo, as empresas necessitam de maior liberdade para que impulsionem seus investimentos, de maneira a obter lucro e prosperar no mercado econômico.

Assim, todas as vezes que o Estado intervier nas práticas empresariais, de certo modo, afetará a liberdade das empresas, externamente, podendo, portanto, gerar efeitos na estrutura empresarial, no modo de atuação no mercado das organizações e, até mesmo, em seus lucros líquidos, como consequência.

Parte dos estudiosos do capitalismo e do crescimento das empresas considera que as organizações não devem se submeter às intervenções externas, incluindo-se aí a do Estado, tendo em vista que seu objetivo maior (lucro) pode ser alcançado de maneira mais producente e eficaz, se a própria empresa determinar as diretrizes de sua atuação. 
Robert Reich (2008), em sua obra "supercapitalismo", identifica que, no cenário atual do capitalismo, as empresas ou se propõem a debater e se alinhar com causas morais e éticas, ou, simplesmente, por experiências anteriores não muito satisfatórias, se afastam dessas discussões, a fim de garantir maior procura por parte dos vários nichos de consumidores.

Nessa esteira, o trabalho se propõe a analisar que a intervenção estatal no Brasil, por meio da Política Nacional de Resíduos Sólidos, com a proposta de operacionalizar o sistema de logística reversa nas empresas, além de democrática - posto que tem por finalidade preservar a garantia ao meio ambiente equilibrado, direito fundamental inserido no rol positivado pelo constituinte originário-, é plenamente compatível com o desenvolvimento das empresas, que necessitam, assim como as pessoas físicas, de se preocupar com a sustentabilidade do planeta.

A interação entre as companhias, a sociedade e o meio ambiente, contudo, é fator que não pode mais ser ignorado no momento atual da civilização. As empresas possuem, assim como todos os formadores do sistema social, responsabilidades com relação ao melhor desenvolvimento do ecossistema, conforme Garbaccio, Krolik e Maciel (2017).

Tal necessidade se vislumbra em um exemplo identificado por Tercek e Adams (2014), ao retratarem parte do sistema natural marinho, como paradigma das espécies-chave. Tais espécies possuem um efeito desproporcional em seus ecossistemas ao se compararem com as espécies comuns, como é o caso das lontras-do-mar do Pacífico. Esses animais, em uma disputa por moluscos, como haliotes, amêijoas e caranguejos, tornamse os predadores.

Caso os predadores quisessem, portanto, vencer essa disputa, poderiam agir, externamente, caçando as lontras até que elas não fossem mais adversários páreos à caça dos moluscos. Ocorre que as lontras-domar do Pacífico também se alimentam dos ouriços-do-mar, ajudando a controlar sua população, de modo que as algas, alimentos dos ouriços, restam preservadas no ecossistema.

Portanto, se os predadores resolvessem caçar as lontras com o objetivo de ficar com todos os moluscos, por consequência natural, haveria menos algas, que são ambiente vital para várias espécies marinhas.

Do mesmo modo, as empresas estão em um sistema cujo funcionamento somente se justifica se outros membros do sistema (consumidores, produtores, distribuidores) estiverem em condições de competir e sobreviver. 
Sem o meio ambiente equilibrado, fator preponderante para a vida dos seres humanos e do ecossistema, como as empresas poderiam exercer o seu papel, se desenvolver e buscar lucros?

As empresas, nesse sentido, se não se engajarem na realização de negócios sustentáveis, de modo a obterem seu próprio "capital natural", na ideia apresentada pelos autores, não terão a mínima perspectiva de subsistência futura, padecendo, pois, pelo perecimento dos recursos advindos do meio ambiente natural "composto pela fauna, flora, solo, água e demais elementos que surgem de forma natural e amoldam-se à natureza", conforme Casagrande Junior e Agudelo (2012).

Os fabricantes e fornecedores, por exemplo, ao inserirem determinado produto no mercado, estão inserindo no meio ambiente natural estruturas construídas pelo homem e não diretamente pelo meio ambiente natural.

Desse modo, o sistema de logística reversa proposto pela PNRS é uma forma de se responsabilizar esses atores para que possam inserir produtos que não sejam despejados ao meio ambiente natural, sem uma destinação final adequada, o que causaria danos ao seu normal desenvolvimento.

Essa atuação das empresas não deve ser considerada como uma forma de limitar o seu desenvolvimento, ou até mesmo prejudicar a sua manutenção material equânime, mas, como uma forma, inclusive, de economia, como quando uma determinada empresa opta por armazenar seus produtos em embalagens mais econômicas e sustentáveis, no sentido de retornarem às empresas para novo armazenamento ou que sejam objetos de reciclagem, o que pode ser realizado por intermédio das associações de catadores, outro princípio basilar que a PNRS trouxe em seu texto.

Tal atitude, além de ser uma forma de garantir a logística reversa de seus produtos artificiais, pode ser também uma forma de redução de custos com produção ou contratos de embalagens, o que naturalmente impulsionaria os seus investimentos, colaborando, pois, com o pleno desenvolvimento da companhia.

Exemplo disso foi apresentado por Tercek e Adams (2014) em sua obra "Capital Natural", quando analisaram a escolha da empresa norteamericana Dow Chemicals, de construir um pântano em suas proximidades, para o tratamento de água.

Eram os meados dos anos 1990, quando uma das empresas da grande companhia Dow Chemicals, localizada em Seadrift, no Estado do 
Texas, após uma pressão regulatória, teve a necessidade realizar melhorias no tratamento de água em suas instalações. $\mathrm{O}$ investimento inicial de tratamento no modo convencional, ou seja, com despejo de bastante concreto e construção, estava previstoem cerca de 40 (quarenta) milhões de dólares, quantia previamente aceita pelos acionistas.

Contudo, um de seus engenheiros teve a ideia de construir um pântano para realizar o integral tratamento de água da unidade empresarial, um caminho alternativo em relação ao comum, que seria gastar uma grande quantidade de dinheiro em algo realizado pelo meio ambiente artificial, no conceito dado por Casagrande Junior e Agudelo (2012).

ADow Chemicals, segunda maior fabricante de produtos químicos do mundo, que opera em 160 (cento e sessenta) países e vendeu, somente em 2011, 60 (sessenta) bilhões de dólares, seguiu a recomendação alternativa do engenheiro e conseguiu, por meio da construção de um pântano, tratar a água de sua unidade por apenas 1,4 (milhões) de dólares, uma economia considerável e que rendeu não só o melhor tratamento de água de sua unidade, mas um menor desequilíbrio na estrutura do ecossistema da localidade, possibilitando, inclusive, a circulação e subsistência de várias espécies da fauna.

Percebe-se, portanto, que a Dow Chemicals, ao optar pela escolha menos agressiva ao meio ambiente, optou,ao mesmo tempo, pelo melhor negócio, que foi bem mais rentável para os seus interesses econômicos, demonstrando uma visão nitidamente empresarial, sem deixar de ser analisado o aspecto ambiental, de modo a conseguir prosperar por mais tempo no mercado, o que demonstraram os estudos de Tercek e Adams (2014), com o número de vendas da empresa, apenas no ano de 2011, portanto, mais de dez anos após essa e outras escolhas pensando no capital social.

O sistema de logística reversa, pois, não deve ser analisado apenas como uma intervenção estatal, que possa prejudicar o desenvolvimento das organizações brasileiras, com reflexos na sua economia, mas sim, como um sistema capaz de, em sintonizando a responsabilidade das empresas com a dos consumidores, agregar valor econômico, com rentabilidade nos fluxos dos produtos, a exemplo, alterar a direção dos negócios empresariais no Brasil, de modo a influenciar o pensamento voltado ao capital natural. 


\section{CONCLUSÃO}

Nem sempre uma intervenção estatal no funcionamento das empresas pode ter, como resultado, algo tendente a prejudicar o seu andamento ou mitigar as suas possibilidades lucrativas. O sistema de logística reversa, ao ser implementado pela Política Nacional de Resíduos Sólidos, se apresenta como uma possibilidade de as organizações seguirem o caminho da sustentabilidade, sem prejudicar o seu desenvolvimento.

Ao proporem o direcionamento das empresas ao capital natural, Tercek e Adams (2014) contribuem parao presente trabalho com a posição de que os esforços das empresas no sentido de se voltarem ao pensamento sustentável, por vezes, podem ser recompensados, não só com a manutenção do ecossistema e melhoria da qualidade de vida da população, mas, também, com a possibilidade de desenvolvimento, nesses moldes, inclusive, econômico, tornando-se, assim, uma possível alternativa rentável às empresas.

Os ambientalistas, ativistas ambientais ou profissionais ligados à ideia de compliance, ao serem integrados às empresas, podem trazer também essa visão desenvolvimentista, de modo a contribuir com uma maior lucratividade, ao mesmo passo em que supera a visão estrita de crescimento pelo lucro. O lucro é a garantia de sobrevivência da empresa; contudo, ele pode e deve, na visão apresentada, ser buscado em conjunto com o respeito ao meio ambiente equilibrado.

Ademais, tal projeção lucrativa e ao mesmo tempo sustentável pode ser realizada mesmo que por meio de uma intervenção estatal, desde que esta seja democraticamente viável. Na visão da democracia participativa, trazida por Coutinho (2016), o sistema de logística reversa se apresenta viável em um Estado Democrático de Direito, pois tende a proteger o Direito Fundamental ao Meio Ambiente Equilibrado, elencado na Constituição Federal de 1988.

O sistema de logística reversa se apresenta, portanto, como uma forma de desenvolvimento das empresas, de modo que estas podem, ao realizar o proposto pela legislação, não apenas propor ideias novas e sustentáveis, mas, também, manter o desenvolvimento competitivo, o que vai lhes proporcionar lugar no mercado, tal qual o exemplo apontado no presente artigo. 


\section{REFERÊNCIAS BIBLIOGRÁFICAS}

BAUMAN, Zygmunt. Modernidade Líquida. 1a ed. Rio de Janeiro: J. Zahar Ed., 2001

BRASIL, Constituição Federal de 1988. Disponível em: <http://www. planalto.gov.br/ccivil_03/constituicao/constituicaocompilado.htm>. Acesso em 20 de outubro de 2017.

BRASIL, Decreto $n^{\circ} 7.404 / 2010$. <http://www.planalto.gov.br/ccivil_03/ ato2007-2010/2010/decreto/d7404.htm $>$. Acesso em 08 de novembro de 2017.

BRASIL, Lei $n^{\circ}$ 12.305/2010. Dispõe sobre a Política Nacional de Resíduos Sólidos. Disponível em: http://www.planalto.gov.br/ccivil_03/ ato2007-2010/2010/1ei/112305.htm>. Acesso em 10 de outubro de 2017.

BRASIL, Lei $n^{\circ}$ 6.938/81. Dispõe sobre a Política Nacional do Meio Ambiente. Disponível em: <http://www.planalto.gov.br/ccivil_03/leis/ 16938.htm>. Acesso 12 de outubro de 2017.

BRASIL, Lei $n^{\circ}$ 9.974/2000. Dispõe sobre a experimentação e pesquisa de embalagens e rotulagens. Disponível em: <http://www.planalto.gov. br/ccivil_03/leis/L9974.htm>. Acesso em 12 de outubro de 2017.

CASAGRANDE JUNIOR, Eloy Fassi; AGUDELO, Libia Patrícia Peralta. Meio Ambiente e Desenvolvimento Sustentável. Curitiba: Editora LT, 2012.

COUTINHO, Carlos Marden Cabral; DE MORAIS, José Luis Bolzan. Direito fundamental ao meio ambiente como elemento constitutivo da democracia. In: Revista Veredas do Direito, Belo Horizonte, v.13, n.25, jan/abr de 2016. Disponível em: <http://www.domhelder.edu.br/revista/ index.php/veredas/article/view/564/480>. Acesso em 02/10/2017.

GARBACCIO, Grace Ladeira; KROLIK, Christophe; MACIEL, Ana Caroline de Moura. Sustainability: The search for the balance between socio- 
enviromentalresponsability and business economic efficency. In: Revista de Direito Público, Porto Alegre, v.14, n.77, set-out 2017. Disponível em <https:// www.portaldeperiodicos.idp.edu.br/direitopublico/article/view/3050/1471>. Acesso em 12/11/2017.

GRECO, Rodrigo Azevedo; FERRAZ JÚNIOR, Tércio Sampaio. Direito e entropia. 2008.[s.n.], São Paulo: 2008.

HAYEK, Friedrich August Von. O Caminho da Servidão.Trad. Ana Maria Copovilla et al. São Paulo: Instituto Ludwig Von Mises Brasil, 2010.

MACHADO, Paulo Affonso Leme. Direito ambiental brasileiro. 20.Ed. São Paulo: Editora Malheiros, 2012.

REICH, Robert B. Supercapitalismo: como o capitalismo tem transformado os negócios, a democracia e o cotidiano. Rio de Janeiro: Elsevier, 2008.

ROSENFIELD, Denis Lerrer. Justiça, democracia e capitalismo. $3^{\text {a }}$ reimpressão. Rio de Janeiro: Elsevier, 2010.

TERCEK, Mark R.; ADAMS, Jonathan S. Capital natural: como as empresas e a sociedade podem prosperar ao investir no meio ambiente. São Paulo: Alaúde Editorial, 2014.

VIDAL, Francisco Baqueiro. Um Marco do Fundamentalismo Liberal: Hayek e o caminho da servidão. In: ObservaNordeste, Recife, 2007. Disponível em: $<\mathrm{http}: / /$ www.fundaj.gov.br/index.php?option $=$ com_content\&view $=$ article\&id $=1695 \%$ 3Aum-marco-do-fundamentalismo-neoliberal-hayek-e-o-caminho-da-servidao$\&$ catid $=58 \&$ Itemid $=414>$.

Artigo recebido em: 17/02/2018. Artigo aceito em: 25/06/2018.

\section{Como citar este artigo (ABNT):}

NASCIMENTO, J. R. H.; LIMA, R. A. O SISTEMA DE LOGÍSTICA REVERSA COMO FORMA DE DESENVOLVIMENTO DAS EMPRESAS BRASILEIRAS: O CAMINHO DO CAPITAL NATURAL. Veredas do Direito, Belo Horizonte, v. 15, n. 32, p. 201-217, mai./ago. 2018. Disponível em: <http://www.domhelder.edu.br/revista/index.php/ veredas/article/view/1247>. Acesso em: dia mês. ano. 